\title{
BIPOLARIZAÇÃO : TENDÊNCIAS EXTREMAS DAS OFERTAS E DAS DEMANDAS TURÍSTICAS ATUAIS
}

\author{
N. Anido Freire \\ Professora no ISC School of Management of Paris \\ France \\ n.freire@wanadoo.fr
}

\section{RESUMO}

No contexto atual de crise financeira e econômica caracterizada na maioria dos países europeus por uma depressão sócio-econômica, uma taxa de paro crescente e um baixo poder aquisitivo, os setores econômicos têm vindo a se ressentir e a constatar que, além da baixa sensível das operações de compra/venda, se está assistindo a uma mudança dos usos de consumo em todos os setores. Com efeito, os consumidores pretendem continuar a consumir, de ser possível como dantes, tanto do ponto de vista quantitativo do que qualitativo mas pagando uma menor quantia. Concomitantemente, os consumidores são cada vez mais exigentes, pelo fato de estarem mais e melhor informados através dos médias e, pela rapidez com a qual dita informação circula através do mundo. O setor turístico não escapa a esta regra atual. Neste trabalho analisaremos as tendências atuais das ofertas do turismo de luxo e do turismo low-cost.

Palavras chave: Bipolarização turística. Turismo de luxo. Low-cost. Yield management. 


\title{
POLARIZATION: EXTREME TRENDS OF THE CURRENT SUPPLY AND DEMAND
}

\author{
N. Anido Freire \\ Professora no ISC School of Management of Paris \\ France \\ n.freire@wanadoo.fr
}

\begin{abstract}
In the current context of financial and economic crisis - characterized in most European countries by a socio-economic depression, rising rates of unemployment and low purchasing power - economic sectors have realized that besides the significant fall of purchase and sale transactions, there is a significant change in the patterns of consumption in all sectors. In fact, consumers wish to continue consumption under the same quality and quantity, but paying a lower price. In addition, consumers become more demanding, which might be explained because they are better informed by mass media and because of the rapid spread of such information through the world. The tourism sector does not escape this trend. In this article we analyze current trends in the luxury tourism and lowcost travel.
\end{abstract}

Key words: Tourism bipolarization. Luxury Tourism. Low-cost. Yield management. 


\section{INTRODUÇÃO}

Desde 2007, a crise financeira e econômica mundial acarretou modificações nos diversos setores da economia e mais particularmente no setor do Turismo, no qual as transformações operadas são flagrantes pois as duas extremidades da cadeia se desenvolvem continuamente : a do Turismo de Luxo (TL) e a do Turismo low-cost (Tlc), não só no âmbito das companhias de transporte e dos operadores turísticos (TO), mas também no domínio da Hotelaria e do comportamento dos clientes (reserva, compra). Estes câmbios se traduzem obrigatoriamente num alargamento dos novos nichos de mercado.

Por outra parte, a instantaneidade da informação permite abolir as fronteiras entre o real e o virtual. Assim, no momento de proceder à reserva dum bilhete de avião ou dum pernoitamento num hotel, as informações e as ferramentas informáticas postas ao dispor do internauta/turista se encalçam sobremaneira.

Apesar da crise, a França continua a ser o primeiro destino turístico mundial. Em 2008, as entradas de turistas registradas nos aeroportos de Paris, atingiram os 87 milhões em 2010, esta cifra baixou a 83 milhões (Lesourd \& Roll, 2010). No entanto, 2011 foi para a França um ano de freqüentação recorde nos hotéis de luxo não só parisienses mas naqueles de todo o território. No que diz respeito à origem dos turistas estrangeiros tendo Paris como destino turístico, se comprovou mais uma vez que os três primeiros lugares são ocupados pelos norte americanos, sul americanos e europeus (britânicos e italianos essencialmente) e que o número de turistas chineses e russos continuou a aumentar.

Enquanto o número de pernoitamentos registrados em 2011 (37 milhões) acusa um incremento percentual de $3,1 \%$ em relação ao de 2010 , o lucro médio $(126,6 €)$ por quarto disponível registrou um aumento de 10,3\% . Na década 1999-2009, o incremento do número de quartos classificados "zero estrela" foi de $100 \%$, os de 3,4 e $5^{*}$ foi de $10 \%$ enquanto que os de $5 *$ registraram um aumento de $50 \%$ (IAU, 2010). Nas duas extremidades da cadeia das hospedagens turísticas, foram constatados incrementos da chamada "taxa de ocupação hoteleira" : de 73,8\% nos hotéis econômicos (baratos) e de $78,6 \%$ nos hotéis quatro estrelas.

Ora, como se pode explicar tal incremento num contexto de grave crise e de desânimo mundial da população ? Obviamente, as pessoas ricas, não têm de se preocupar com as crises, as falências empresariais e os despidos maciços de trabalhadores visto que o seu estatuto permanece invariável e elas não se apercebem de nada. No tocante às pessoas de classe média e baixa, em época de crise elas pretendem no entanto desfrutar de férias para esquecer momentaneamente a crise, mas a um preço acessível, mesmo se elas se vêem forçadas a reduzir : 
- Quer o tempo de estada turística, preferindo as permanências de 3 ou 4 dias,

- Ou a distância percorrida, escolhendo destinos turísticos mais próximos do lugar habitual de morada,

- Quer a categoria do hotel, camping ou residência no habitante,

- Ou a freqüentação de restaurantes, preferindo então os piqueniques ou a fórmula aparthotel,

- Quer ainda os lazeres e as visitas anexas.

Neste trabalho, analisamos a bipolaridade do setor turístico baseando-nos só no caso da França : na primeira parte, apresentamos a evolução recente do turismo e da hotelaria de luxo e na segunda, a das companhias aéreas low-cost (CLC), examinando as causas e as especificidades da gestão de ambos tipos extremos de turismo, sem esquecer de salientar as influências positivas da crise econômica e financeira atual. Após uma discussão sobre as características, a evolução e as vantagens de ambos pólos do turismo, concluímos sobre as condições a serem respeitadas para evitar que uma viagem ou uma estada turística de sonho se transforme num pesadelo.

\section{O turismo de Luxo na França}

O turismo de luxo possui as mesmas características do setor do luxo em geral.

"O luxo é o conjunto de atividades econômicas destinadas à criação de bens (produtos, artigos) e de serviços cujo caráter excepcional, caro e suntuoso traduz a sua pertença a uma esfera particular e destinados a uma clientela que exige qualidade, arte, beleza, refinamento e requinte extraordinário, visto a sua aquisição ser sinônimo de bem-estar “ (Anido Freire, 2010).

Para satisfazer as demandas e as exigências de um número crescente de turistas de elite, a França teve que alargar as suas ofertas hoteleiras de gama alta e de luxo; é por isso que começou a construir e/ou a renovar prédios de grande valor, adaptando-os para o seu novo uso (Hoibian \& Hatchnel, 2010).

Quadro ${ }^{\circ} 1$ - Hotéis de gama elevada e de luxo construídos recentemente e previstos na França

\begin{tabular}{|c|l|l|}
\hline Ano de construção & $\begin{array}{l}\text { Cidade Francesa e patrimônio } \\
\text { arquitetônico }\end{array}$ & $\begin{array}{l}\text { Nome do hotel, categoria e número } \\
\text { de quartos }\end{array}$ \\
\hline 2007 & Bordeaux & Grand Hôtel Régent \\
\hline 2008 & Toulouse & Hôtel du Grand Balcon \\
\hline 2009 & Toulouse & Hôtel Radisson \\
\hline
\end{tabular}




\begin{tabular}{|c|l|l|}
\hline 2011 & Montpellier & Crowne Plazza \\
\hline 2012 & Nantes (antigo Palácio da Justiça) & $\begin{array}{l}\text { Radisson (4*) } \\
142 \text { quartos, 20 suítes }\end{array}$ \\
\hline 2013 & $\begin{array}{l}\text { Marselha (antigo Hôtel Dieu, } \\
\text { classificado "monumento } \\
\text { histórico") }\end{array}$ & $\begin{array}{l}\text { Grupo Britânico Intercontinental } \\
\text { (Palácio 5*) 194 quartos, 15 suítes }\end{array}$ \\
\hline 2014 & Lyon (ex Hospital de l'Antiquaille) & La Villa Maïa (5*) \\
\hline meados de 2014 & Strasbourg & Marriott Rennaissance \\
\hline $2014-2015$ & $\begin{array}{l}\text { Valenciennes (antigo Hospital du } \\
\text { Hainaut, classificado "monumento } \\
\text { histórico" do século XVIII) }\end{array}$ & $\begin{array}{l}\text { Hotel (4 ou 5*) e um Palácio de } \\
\text { Congressos }\end{array}$ \\
\hline 2016 & Lyon (antigo Hôtel Dieu) & $\begin{array}{l}\text { Intercontinental (5*) } \\
147 \text { quartos }\end{array}$ \\
\hline
\end{tabular}

Fonte : Ministère de l'Artisanat, du Commerce et du Tourisme (France).

Os hotéis de gama elevada e de luxo escolhem as suas implantações não só nos "destinos turísticos faros", simbolizados em França por Paris e a Côte d'Azur, mas também nas outras cidades e regiões (Quadro 1). Por outra parte, este desenvolvimento hoteleiro da gama elevada apresenta uma indiscutível vantagem (IAU, 2010) para cidades tais como Estrasburgo que não possuía nenhuma estrutura hoteleira 5 estrelas. Além de se tratar dum investimento misto importante (34 milhões $€$ ), resultante da parceria entre o grupo imobiliário Da Vinci e o grupo hoteleiro Marriott, dita construção permitirá acrescentar à oferta hoteleira mais 105 quartos e, ao mesmo tempo, renovar um prédio histórico (l'Ancien Commissariat Central), situado no coração do velho Estrasburgo (Ducuing, 2012). A importância mediática e governamental outorgada a este projeto, acordou o interesse de outros grupos hoteleiros por esta capital européia : o grupo Sheraton mostrou focar o seu interesse no bairro de negócios Wacken, situado ao lado do Parlamento Europeu.

A França estabeleceu uma reforma da classificação hoteleira (lei do 2 de julho de 2009) não só com o fim de desenvolver e modernizar o parque hoteleiro, mas também para satisfazer a demanda da clientela nacional e internacional, permitindo assim atingir um triplo objetivo :

- melhorar a visibilidade e a qualidade da oferta hoteleira francesa,

- harmonizar a classificação dos estabelecimentos de gama alta com as práticas internacionais através da criação da categoria $5^{*}$ até lá inexistente na França,

- modernizar as infra estruturas do setor hoteleiro francês. 
É importante sublinhar que na França, a denominação de Palácio ("Distinction Palace") para um hotel de categoria superior às $5^{*}$, é outorgada pelo Ministro encarregado do Turismo e até hoje são só doze hotéis que a receberam :

Quadro 2 - Hotéis franceses tendo recebido a "Distinção Palácio"

\begin{tabular}{|l|l|}
\hline Nome dos Hotéis com a "Distinção Palácio" & Localização \\
\hline Hôtel du Palais & Biarritz \\
\hline Hôtel Les Airelles & Courchevel \\
\hline Hôtel Le Cheval Blanc & Courchevel \\
\hline Hôtel Le Bristol & Paris \\
\hline Four Seasons, Hôtel George V & Paris \\
\hline Hôtel Le Meurice & Paris \\
\hline Hôtel Le Park Hyatt & Paris-Vendôme \\
\hline Hôtel Le Plaza Athénée & Paris \\
\hline Hôtel Le Ritz & Paris \\
\hline Hôtel Le Crillon & Paris \\
\hline Hôtel Le Fouquet's - Barrière & Paris \\
\hline Hôtel Le Mandarin Oriental & Paris \\
\hline Hôtel Le Peninsula & Paris \\
\hline Hôtel Le Royal Monceau- Raffles & Paris \\
\hline Hôtel Le Shangri-La & Paris \\
\hline Le Grand Hôtel & Saint-Jean-Cap-Ferrat \\
\hline
\end{tabular}

Fonte : Ministère de l'Artisanat, du Commerce et du Tourisme (France).

Esta distinção é outorgada a hotéis de superluxo, isto é, cuja categoria ultrapassa em demasia a das $5^{*}$ e que possuem :

- Uma situação geográfica espetacular,

- Um interesse histórico excepcional,

- Uma estética e/ou um patrimonial particular,

- Uma excelência de serviços à medida.

\section{As causas do turismo de luxo}

Indubitavelmente, os ricos são o alvo do turismo de luxo. Em 2009 o número total de milionários mundiais era de 10 milhões; tinha portanto aumentado de $17 \%$ (cap Gemini \& Merryl Lynch, 2010) em relação ao ano precedente, e em 2010 o aumento foi de $8 \%$. Em 2011 se estima que há 11 milhões de milionários no mundo. 
O desenvolvimento contínuo da hotelaria de luxo em Paris e na França não admira visto a tradição histórica da hotelaria de luxo e do indiscutível saber e saber fazer da gastronomia e da enologia francesa. Aliás na terminologia culinária e gastronômica assim como também nas Escolas de Hotelaria de prestígio internacional, achamos a presença ou a grife dos grandes Chefes franceses : Bocuse, Vatel, Maxim's, etc.

No entanto, é inegável que para contrabalançar a aquisição recente e maciça de hotéis franceses de luxo de renome internacional por poderosos homens de negócios essencialmente árabes e chineses, e defender assim o prestígio da hotelaria de luxo e de gama alta senão $100 \%$ francesa, pelo menos franco-européia, as parcerias de grupos hoteleiros, de empresas de construção (Eiffage, Bouygues, Maïa), de financeiras (Cogedim, Axa, Vauban) e das autoridades locais e regionais, permitem tais investimentos e tais construções e renovações.

Da mesma maneira que os outros segmentos do luxo tais como a joalharia, alta costura, perfumaria, marroquinaria, fabricação de cristais e de porcelana, os hotéis de luxo põem de relevo o caráter único e excepcional dos seus bens, produtos e serviços, cuja qualidade é conhecida, reconhecida e respeitada pela clientela e pelos concorrentes. Uma marca ou uma grife de renome internacional não tem preço : a imagem da marca vai a par da qualidade. Quem pernoita num hotel de luxo se identifica tanto à grife que acaba se sentindo duma certa maneira como o seu proprietário : é o que poderíamos chamar sentimento de pertença e de identificação (Anido Freire, 2010) que lhe permite atingir um excepcional estado de bem-estar, de satisfação e orgulho pessoal.

\section{A gestão empresarial do turismo de luxo}

Visto que no turismo de luxo, as atividades se concentram nos produtos e serviços de gama alta e de luxo, o principal requisito é uma especialização máxima, um aprimorar, um requinte e até por vezes uma sofisticação e personalização levadas ao extremo. Os hotéis de luxo, os Palácios, os castelos, os palacetes particulares, os hotéis navegantes ("péniches", iates, veleiros) despendem fortunas para satisfazer uma clientela internacional, caprichosa e fantasista, à procura de experiências e sensações inéditas e por conseguinte, sumamente dispendiosas.

Segundo a Eurostaf (2004), para considerar que um cliente pertence ao Turismo de luxo, é necessário que as suas despesas diárias para se alojar num hotel sejam equivalentes ou superiores a um limiar fixado a $550 €$. Esta quantia diária de $550 €$ é $22 \%$ superior às despesas de alojamento hoteleiro duma clientela normal, ou seja $25 € X 22$. Com efeito, o custo de um pernoitamento num hotel desprovido de estrelas é de $25 €$. É o chamado «coeficiente multiplicativo"; ele permite calcular o grau de cada categoria do luxo. 
Nesta categoria de hotéis, além dos quartos de luxo, existem as suítes, as quais por sua vez podem ser "Suítes Reais" ou "Suítes Diplomáticas": o seu preço diário vai de $3000 €$ até $32000 €$ por uma noite parisiense inesquecível. Portanto o preço pago por um produto de luxo ou por um serviço turístico de luxo é o único critério retido para considerar um turista de luxo.

No setor do turismo de luxo, a importância dos custos equivale às despesas efetuadas, em ordem decrescente, nos âmbitos :

- Da Hotelaria,

- Da restauração,

- Das salas de jogo e cassinos,

- Do aluguer de carro.

A maioria dos hotéis de luxo franceses pertencem ao patrimônio arquitetônico : carregados de história quer gloriosa, quer trágica, mas sempre impregnados de charme, beleza e distinção, eles são capazes de ressuscitar as cenas e as personagens do passado para as reencarnar melhor no presente.

Visto o turismo de luxo ser ressentido pelo turista da classe média como uma excepcionalidade inatingível, mas pelos turistas provenientes das classes elevadas como uma situação normal e inclusivamente banal, as grifes e os grupos dedicados a este setor tentaram sublimar a sua especialização e a sua diferenciação.

Esta atitude e as técnicas de organização e de gestão conseqüentes lhes permite exercer a sua profissão com uma clientela seleta e privilegiada. É aliás através destas características que se estabelece a diferenciação entre o turismo de luxo inacessível (verdadeiro ou permanente) e o turismo de luxo medianamente acessível (ocasional). O grupo Thomas Cook constitui um exemplo que pertence a este último tipo de turismo pois ele controla todo o processo turístico desde a produção até à distribuição (hotéis, companhias aéreas, redes de distribuição) : é a chamada "integração vertical" (Monereau, 2008).

\section{O turismo low-cost}

Historicamente, a noção do low-cost aéreo surgiu nos EUA na década de 1970, com a criação da companhia aérea Southwest Airlines. Ela pretendia assim ocupar um nicho de mercado regional para o qual a American Airlines não tinha mostrado muito interesse, visto se tratar de vôos de curta duração (1 hora). Foi um verdadeiro êxito. Com efeito, dita companhia, pioneira do conceito "preços baixos", continua hoje em dia a assegurar a ligação entre as três grandes cidades do Texas : Houston, Dallas e San 
Antonio e ocupa o primeiro lugar nestas ligações domésticas regionais.

O turismo low-cost registrado nos aeroportos de Paris passou de 4,5\% em 2004 a $11 \%$ em 2010, ou seja em seis anos houve um aumento de 135\% (Lesourd \& Roll, 2010).

\section{As causas do low-cost na França}

Quais foram as motivações ou as causas que levaram à criação das companhias aéreas low-cost (CLC)? Consideramos que foram as seguintes :

- A necessidade de criar uma oferta inexistente e, no entanto, indispensável para os turistas/consumidores : a de assegurar uma ligação aérea de proximidade, quer local, quer regional. Geralmente, para as grandes companhias aéreas os vôos domésticos são não rentáveis.

- A vontade explícita de propor aos clientes um número e uma categoria de serviços mais ou menos equivalente àqueles oferecidos pelas companhias da concorrência, mas com preços excepcionalmente baixos e por conseguinte atraentes para o consumidor.

- Apesar de afixar preços imbatíveis, as CLC pretendem mais do que sobreviver, resgatar margens de benefício, de ser possível idênticas às da concorrência.

Obviamente, na época de crise atual, estes preceitos são mais do que nunca duma evidência notória. Comprova-se uma modificação do comportamento dos turistas franceses : eles preferem ir de férias menos longe, durante menos tempo e pagar menos dinheiro (Hoibian, 2010). É aliás o que explica o aumento do mercado low-cost na França.

No caso da França, os concorrentes da Air France são easyJet e Ryanair. Ambas companhias monopolizam progressivamente o mercado do "curto correio", isto é, dos vôos intra europeus. De tal forma que, apesar da fusão Air France-KLM (grupo AllianzStar), a companhia nacional francesa perde os seus segmentos de mercado em detrimento das outras duas que se encarregam de os recuperar.

\section{A gestão empresarial do low-cost}

De que maneira as CLC conseguem reduzir, baixar e até quebrar os preços?

- Mesmo se historicamente, os abatimentos de preço sempre existiram no âmbito do transporte turístico em geral, e mais particularmente no aéreo, eles adotavam a forma de rebaixas ou descontos específicos ou nominativos, para certas categorias sócio econômicas ou profissionais (familiares dos empregados das próprias companhias) e eles eram menos numerosos. 
- Contrariamente ao que fazem as grandes companhias que visam a diversificação constante dos seus produtos, as CLC simplificam e limitam as suas ofertas, concentrando-as em determinadas zonas ou destinos turísticos. Elas agem a dois níveis, empresarial e relação cliente, e conseguem assim :

\section{No nível empresarial :}

- simplificar a estrutura organizacional da empresa : diminuição do tamanho e da hierarquização (organograma quase horizontal),

- reduzir o pessoal ao estritamente necessário e implicá-lo na performance da empresa (Bamber, Gitell, Kochan \& Von Nordenflycht, 2009),

- recrutar jovens pois eles são menos exigentes do ponto de vista salarial,

- reduzir drasticamente o número de lojas,

- exigir aos responsáveis comerciais a utilização intensa de internet (Fulghum, 2011),

- limitar o mais possível as despesas de comunicação e publicidade,

- reduzir os custos e poder assim baixar os preços (alvo principal das CLC).

No nível da relação cliente :

- simplificar as ofertas e facilitar a escolha do consumidor,

- oferecer uma boa relação qualidade/preço

- responsabilizar o consumidor que deve executar a reserva e a compra através da internet,

- suprimir o serviço de restauração a bordo e a gratuidade das bagagens,

- satisfazer os clientes : fidelização à marca CLC.

- Outro argumento importante que permite explicar a redução de custos empresariais resulta da frota utilizada por estas companhias : a norteamericana Southwest utiliza desde 1971 os aviões Boeing 737 e a européia easyJet aviões Airbus A319 e A320. Esta escolha lhes permite evitar as despesas habituais das grandes companhias aéreas consagradas à compra de novos aviões de maior performance, à sua manutenção e à formação dos pilotos, co-pilotos, técnicos de navegação e tripulação.

- A redução drástica dos custos Marketing por cliente (em todos os níveis e componentes do Marketing) diferencia as CLC das grandes companhias. Para Air France/KLM que conta 100000 empregados o seu volume de negócios (VN) é de 24 mil milhões $€$, enquanto que para easyJet que tem 7360 pessoas o seu volume de negócios é de 4 mil milhões $€$. Dito por outras palavras, o VN/empregado de easyJet é duas vezes superior ao de Air France/KLM (Escande, 2012). Com efeito :

- Air France/KLM : 24 mil milhões $€ / 100000=24000 € /$ empregado

- easyJet : $\quad 4$ mil milhões $€ / 7360=54347 € /$ empregado 


\section{DISCUSSÃO}

Como se pode explicar a coexistência simultânea de um interesse de desenvolvimento turístico bipolar em França?

Julgamos que se trata em realidade de uma necessidade atual de desenvolver ambos pólos de turismo com o intuito de satisfazer as demandas de dois tipos de clientes : os ricos e os de médio e baixo poder aquisitivo.

\section{Necessidade e vantagens de desenvolver o turismo de luxo}

Visto que a França é o primeiro destino turístico mundial e que registrou nos últimos cinco anos um incremento de turistas ricos, oriundos dos Estados Unidos, dos Emiratos Árabes Unidos, da Grã-Bretanha, da Itália, da China e do Brasil foi preciso alargar o parque hoteleiro de luxo.

Tradicionalmente, os hotéis e as residências de luxo costumam instalar-se em cidades e bairros prestigiosos ou em sítios excepcionais, o que favorece o desenvolvimento territorial e citadino melhorando as infra estruturas turísticas. Isto explica as motivações do súbito interesse dos grupos hoteleiros nacionais e internacionais pelos prédios antigos, por vezes vetustos, das principais cidades francesas.

- No decurso da última década, o movimento de renovação dos prédios históricos e arquitetônicos, ora velhos, ora um pouco degradados constitui não só um ganho inesperado para as autarquias francesas sobretudo nesta época de crise e de sobre endividamento nacional mas ele permite "matar não dois, mas vários coelhos duma cajadada". Com efeito elas :

- conservam e salvaguardam o patrimônio nacional e/ou regional, dum valor inestimável, sem embora perder o seu controle.

- alargam a capacidade do parque hoteleiro de gama elevada e de luxo, multiplicando assim as suas possibilidades de acolhimento de turistas de elevado poder aquisitivo.

- conseguem modernizar a cidade (zona antiga e zonas portuárias) : a metamorfose urbana, econômica e cultural conduz a um novo ordenamento territorial (Vera Rebollo \& Ivars Baidal, 2009) com novas regras de circulação automobilística e pedestre e criação de espaços verdes (Merlin, 2008).

- reforçam a imagem de marca da cidade e da região aos olhos do turista e concomitantemente, a identidade e o orgulho dos cidadãos (ufanismo, bairrismo).

- A reabilitação destes "bâtiments historiques de charme" (construções históricas de charme), permitiu criar em França uma nova categoria hoteleira : os "Hôtels de caractère" (Hotéis com forte personalidade). 
- Não são só os intervenientes diretamente relacionados com o Turismo que beneficiarão do extraordinário maná financeiro acarretado pelos turistas, mas todos os setores da economia.

Portanto, o desenvolvimento e os contributos financeiros gerados pelas atividades turísticas provocarão um aumento do poder de compra dos habitantes locais o que lhes permitirá atingir um bem-estar (well-being).

- Em último lugar, existem em França numerosos exemplos de criação recente de "verdadeiros pólos de atração múltiple", além da turística :

- Reims, capital da região champenoise cuja Catedral de renome histórico e religioso é internacionalmente conhecida pela sua rosácea e seus vitrais e onde também se produz o famoso Champagne, tornou-se desde junho de 2007 uma cidade dos subúrbios de Paris, graças à ligação de trem de alta velocidade (TGV) que assegura o percurso Paris-Reims em tão só 45 minutos.

- Estrasburgo, há alguns anos sinônimo simplesmente de sede do Parlamento Europeu, enaltece hoje a riqueza da sua arquitetura (Catedral e o seu famoso relógio astronômico), a beleza medieval do seu bairro "La Petite France", assim como também o seu patrimônio gastronômico e enológico (Rota dos Vinhos Alsacianos). Mas é sobretudo o "Marché de Noël" (Mercado de Natal, cujos inícios datam de 1570) que atrai a vinda anual de mais de dois milhões de turistas mundiais.

\section{Necessidade e vantagens de desenvolver o turismo low-cost}

O conceito de CLC surgiu nos EUA para facilitar o transporte regional posto de lado pelas grandes companhias aéreas e em ausência de outros tipos de transporte convenientes. Ora, os EUA e o Brasil têm muitas semelhanças : divisão em Estados dirigidos por governadores, enorme extensão territorial na qual a cobertura ferroviária e rodoviária são escassas: é portanto o terreno ideal para a implantação das CLC aéreas. Em França e na UE em geral, a rede ferroviária é vasta e o desenvolvimento dos serviços de Alta velocidade (TGV em França, AVE na Espanha) permitem transportar milhões de passageiros, encurtando as distâncias e obtendo um ganho de tempo. No entanto, a moda das CLC levou à criação de três companhias aéreas cuja vida foi relativamente efêmera : Air Inter (1957-1997), AOM (1991-1999) e Air Liberté (1987-2003).

Com o advento da crise, surgiu o conceito do "turismo low-cost" que se espalhou depressa no mundo e foi adquirindo uma conotação de democratização do Turismo. Ressurgiram então as CLC mas com outra "filosofia" : a sua vocação não é a de estabelecer ligações de curta distância, mas a de oferecer um serviço aéreo de boa relação qualidade/ 
preço tanto no curto, como no meio e longo correio, nomeadamente aos turistas de baixo poder de compra. O desenvolvimento do turismo low-cost conduz a um tipo diferente de ordenamento do território, alargando os aeroportos já existentes ou criando novos (Allain \& Ben Omrane, 2004), assim como também novas estações ferroviárias (TGV).

O low-cost constitui a moda dos nossos dias (Devignes, 2010), de tal forma que toda a gente, independentemente do seu nível sócio econômico e do seu poder de compra deve ter o direito de beneficiar de férias e de poder viajar com o fim de conhecer outros países e culturas e de descansar e se divertir.

Os diversos intervenientes do setor do turismo compreenderam logo que o low-cost constitui um nicho de mercado muito rentável. Tentaram e continuam a tentar alargar cada vez mais a gama de ofertas de produtos turísticos e não vacilam em abolir as barreiras e os interditos para propor aos turistas de baixo poder aquisitivo, produtos que num passado recente pertenciam ao setor do turismo de luxo. Os operadores turísticos, as companhias de transporte aéreo e marítimo e os grandes grupos hoteleiros nacionais e internacionais, propõem nos quatro cantos do mundo, excursões, viagens e estadas a preços incrivelmente baixos que constituem verdadeiras pechinchas. Com a ajuda dos especialistas do yield management, eles conseguiram rentabilizar o setor do turismo, evitando os assentos vazios nos transportes e os quartos vagos nos hotéis, reduzindo os preços ao máximo e criando tabelas de preços múltiples.

Ao lado da vantagem de uma indiscutível lotação assegurada de antemão, surgiram dois problemas que foram rapidamente homologados a inconvenientes : o do overbooking (sobre reserva ou reserva em demasia) e o da mistura de clientelas turísticas apresentando um perfil social, profissional, cultural e econômico muito diferente e freqüentemente oposto. Assim, na classe econômica dum mesmo vôo viajam turistas de classe média alta, média tradicional e média baixa que desembolsam quantias muito diversas e que, no entanto recebem os mesmos serviços, tratamento e atenção da parte da tripulação. A classe "Negócios", herdeira direta da antiga "Primeira classe", está reduzindo sobremaneira o seu espaço de tal forma que basta só uma dúzia de assentos. Coabitam num mesmo recinto espacial (cabina do avião), separados por uma simples cortina, diversos mundos num mesmo espaço temporal (tempo do vôo). Ora, dita democratização é ressentida por certos turistas como injusta pois julgam o tarifário nada democrático.

As técnicas do marketing low-cost e do yield management aplicadas também em certos hotéis de luxo e nos chamados "hotéis navegantes", isto é os cruzeiros de luxo, são idênticas às das CLC. De tal forma que num cruzeiro ou num hotel de renome e de categoria coabitam simultaneamente, uma clientela de alta distinção, outra de classe média e outra de classe baixa. Este fenômeno pode em parte também justificar que a partir das queixas apresentadas e das sugestões assinaladas nos inquéritos de satisfação, 
certos grupos hoteleiros tenham decidido construir mais hotéis de luxo requintado, exclusivamente reservado às elites, visto a inacessibilidade dos seus preços : é o caso dos "Palaces" (Quadro 2). Para se afastar ainda mais dos outros hotéis e para serem ainda mais elitistas, eles não só selecionam a sua clientela a partir do seu poder aquisitivo mas também personalizam extremadamente os seus serviços para satisfazer as exigências e os sonhos de determinadas nacionalidades e/ou profissões.

Perante a agravação da crise e com o alvo de poder satisfazer as demandas cada vez mais exigentes dos turistas de baixo poder de compra, as autoridades e os gestores turísticos continuam a alargar as ofertas de turismo low-cost, acrescentando novas fórmulas e pacotes "tudo incluído". Por exemplo, os campismos que propõem além da piscina, serviços de Spa e de cuidados estéticos e corporais são cada vez mais numerosos. Concomitantemente certos campismos, ao verem a sua clientela diminuir no decurso dos últimos anos e ao constatar que as estadas se encurtavam progressivamente, decidiram suprimir quarteirões de bungalows e de cabanas e criar áreas especiais reservadas ao estacionamento de longa duração das caravanas. O mesmo fenômeno está sendo verificado nas estações de esqui francesas e européias que instalam ao pé das montanhas áreas de estacionamento para as caravanas, criando assim uma nova forma de alojamento turístico low-cost : o turismo de "caravaneve" (le caravaneige). Ele é vantajoso para as famílias pois elas podem assim despender no esqui e nas outras atividades anexas o dinheiro poupado no alojamento e nas refeições e, não obstante, se deleitar diariamente duma paisagem exótica gratuitamente.

Podemos afirmar então que o turismo de luxo tenta atrair os ricos e os novos ricos do mundo inteiro e mais especificamente os dos BRIC, enquanto que o turismo lowcost se esforça de atrair as pessoas que não podem ter férias por causa do baixo poder aquisitivo e que na França representam 35\% da população (ANCV \& BVA, 2009). É por isso que a $\mathrm{ANCV}$ favorece $\mathrm{o}$ acesso às férias de 8 milhões de pessoas das quais, 100000 são consideradas como completamente desfavorecidas. 


\section{CONCLUSÕES}

Demonstramos neste trabalho a existência em França de uma bipolaridade crescente do ponto de vista numérico do setor do turismo. Esta bipolaridade está presente em todos os intervenientes turísticos e em todos os níveis das gamas turísticas. Constatamos que as tendências extremas das ofertas e das demandas turísticas estão atualmente se afastando cada vez mais e que o mercado do turismo internacional está se distribuindo, antes, se aglutinando em volta dum eixo vertical : no seu topo superior se acha o turismo de gama alta e de luxo e no seu extremo inferior, o turismo low-cost ou turismo de preços baixos e de pechinchas. Estas duas categorias são bem definidas e delimitadas graças a uma diferença de destino turístico, categoria hoteleira, preços, serviços, categoria sócio-profissional da clientela.

Pelo contrário, entre os dois extremos existem ofertas que operam uma mistura de serviços e de qualidades que lhes permite acolher turistas de classes sociais variadas (classes média baixa, média e média alta) e diversas camadas etárias (pessoas idosas, jovens, famílias com crianças), sob pretexto duma democratização necessária do turismo.

Julgamos que no contexto de crise econômica e financeira grave atual é preciso que as autoridades competentes estabeleçam um limiar (de preços, qualidade e seguridade) a não ultrapassar e regulamentem e controlem severamente todos os atores do setor do Turismo para evitar os abusos e as injustiças decorrentes duma inadequação da relação qualidade/preço.

Os profissionais e intervenientes do turismo devem ter uma maior cautela e seriedade e definir claramente a relação qualidade/preço das novas ofertas antes de proceder ao seu lançamento e poder assim satisfazer as diversas tipologias de clientes de maneira irreprochável, evitando as queixas (freqüentes no âmbito do low-cost) e obtendo um valor acrescentado que será benéfico à marca de CLC e às grifes hoteleiras e gastronômicas de luxo. 


\section{BIBLIOGRAFIA}

Allain, V. \& Ben Omrane, T. (2004). Study of Low Cost Traffic Patterns, EUROCONTROL Experimental Centre, EEC Note No. 06/04, 39 p., Brétigny-sur-Orge, France.

Agence Nationale des Chèques Vacances (ANCV) \& Institut d'études de marché et d'opinion (BVA) (2009). Etude sur les publics non-partants en vacances (synthèse), 21 p., Paris

Anido Freire, N. (2010). Singularités de la communication dans le secteur du luxe, CRISC n ${ }^{\circ} 28,11-37$, Paris.

Bamber, G. J., Gitell, J. H., Kochan T. A. \& Von Nordenflycht, A. (2009). Up in the Air: How Airlines Can Improve Performance by Engaging Their Employees, ILR Press, Cornell University Press, 240, NY.

Cap Gemini \& Merryl Lynch (2010). World Wealth Report 2010 (14 ${ }^{\text {th }}$ ed.), $40 \mathrm{p}$.

Devignes, C. (2010). Low-cost \& tourisme, Revue Espaces, Tourisme et Loisirs, n²82, Paris.

Ducuing O. (2012). Les villes offfrent leurs sites historiques à l'hôtellerie de luxe, Les Echos, 22/02/2012, Paris.

Escande, Ph. (2012). Free ou les deux règles d'or du low cost, Les Echos, 18/01/2012, Paris.

Eurostaf (2004). Le tourisme de luxe en France. Paris, France.

Fulghum, D. (2012). Low Cost Is Key To Electronic Warfare Future, Aviation Week, Washington, EUA. (http://www.aviationweek.com/aw/generic/story_channel. jsp?channel=defense\&id=news/awst/2012/01/16/AW_01_16_2012_p38410323.xml\&headline $=$ null\&next $=10$, consulta do 7/4/2012)

Hoibian, S. (2012). Vacances 2010: Les contraintes financières favorisent de nouveaux arbitrages, 79 p., CREDOC, Paris.

Hoibian, S. \& Hatchuel, G. (2010). 2009: avec la crise la recherche des vacances économes se développe, CREDOC $n^{\circ} 262$ (Centre de Recherches pour l'Etude et l'Observation des Conditions de vie), Paris.

Institut d'Aménagement et d'Urbanisme (IAU). (2010). Aménagement et développement touristique. Contribution au schéma régional de développement du tourisme et des loisirs en Ile-de-France, 2010-2020, 66 p., Paris.

Lesourd, J.C. e Roll, P. (2010). Le tourisme à Paris : chiffres clés, 36 p, l'Observatoire économique du tourisme parisien, Paris.

Merlin, P. (2008). Tourisme et aménagement touristique : des objectifs inconciliables?, La Documentation française, $232 \mathrm{p}$.

Monereau, M. (2008). Management des organisations touristiques, 254 p., Bréal, Paris.

Vera Rebollo, J.F. \& Ivars Baidal, J. A. (2009). Spread of Low-Cost Carriers: Tourism and Regional Policy Effects in Spain, Regional Studies, Vol. 43.4, 559 - 570.

Recibido 15/01/2013

Aceptado 30/04/2012

Arbitrado anónimamente 